\title{
ANALISIS MANAJEMEN RISIKO KREDIT SEBGAI ALAT UNTUK MEMINIMALISIR RISKO KREDIT PADA BANK NAGARI CABANG PEMBANTU SIMPANG HARU
}

\author{
Oriza Satifa, Jhon fernos \\ Akademi Keuangan dan Perbankan" Pembangunan" Padang \\ Orizasatifa884@gmail.com
}

\begin{abstract}
This study aims to determine the application of credit risk management and criteria as well as efforts to minimize credit risk in Bank Nagari Simpang Haru Sub-Branch. In implementing credit risk management at Bank Nagari Simpang Haru Sub-Branch, it includes the identification, measurement, monitoring and control of credit risk. Credit risk is the risk of non-performing loans where the debtor must be under special surveillance while the credit measurement must be in accordance with the NPL, Nonperfoming loan (NPL) is very important for credit risk measurement at Bank Nagari Simpang Haru Sub-Branch, because it must be in accordance with the applicable provisions of the Bank Indonesia (BI), by using a non perfoming loan, it will be easy for the Bank to find out the criteria in analyzing credit risk where the Indonesian bank sets a maximum Npl of 5\%. Credit collectability is the basis in calculating the level of NPL. Credit Risk Issues that appear at Bank Nagari Simpang Haru Sub-Branch, namely Problem Loans. In this case there are credit risk factors including internal banks, debtors and others. Thus the debtor becomes a factor that often arises and is of special concern.
\end{abstract}

Keywords: Credit Risk Management, Credit Risk, NPL, Minimizing Credit Risk

\section{PENDAHULUAN}

Menurut undang-undang No. 10 tahun 1998, pengertian Bank adalah badan usaha yang mempunyai peranan menghimpun dana dari masyarakat dalam bentuk simpanan dan kemudian menyalurkan kembali dalam bentuk kredit kepada masyarakat agar dapat membantu masyarakat yang kekurangan dana dalam rangka meningkatkan taraf hidup masyarakat yang lebih baik lagi.

Dalam Dunia perbankan Bank mempunyai peranan yang sangat penting dalam meningkatkan perekonomian suatu Negara, begitupun dalam kehidupan masyarakat yang moderen dalam eraglobal saatini, yang sehari-harinya melibatkan jasa dari sector perbankan untuk melakukan semuatransaksi. Dengan tingkat kepercayaan masyarakat yang begitu tinggi terhadap perbankan terus meningkat setiap tahunya yang di tandai dengan meningkatnya dana dari masyarakat ke sector perbankan. (Kasmir, 2014)

Dengan menigkatnya dana dari masyarakat, perbankanberusaha untukmenciptakansuatuproduk yang baru dalam dunia perbankan yang moderen dan mudah dipahami dengan tujuanmenarikdanmemenuhikebutuhannasabah, 
dengan meningkatkantatakelola sertafungsiidentifikasi permasalahan yang berat dan terencanabagi bank.(Firmansyah \& Fernos, 2015)

Manajemenrisikokredit adalahResiko dari nasabah atau debitur karena tidak mampu dalam mengembalikan hutangnya kepada bank sesuai dengan kontrak yang telah disepakati antara pihak debitur dengan pihak bank. Sedangkan resiko kredit terjadinya karena kualitas kredit semakin menurun, upaya untuk mengurangi kerugian dengan memahami kecukupan modal bank dan cadangan kerugian pinjaman pada waktu tertentu suatu proses yang telah lama menjadi tantangan bagi lembaga keuangan.(Putra, 2015)

Kredit bermasalah merupakan ancaman bagi Dunia Perbankan hal ini menggambarkan penyaluran kredit dapat mengalami resiko kegagalan debitur dalam mengembalikan pinjaman, bertambahnya kredit bermasalah menyebabkan bank mengalami kerugian potensi dan dapat menimbulkan berbagai masalah bagi bank diantaranya masalah liquiditas, solvabilitas, rentabilitas dan biaya-biaya tambahan. Oleh karena itu Manajemen resiko kredit sangat di perlukan untuk mengelola kredit bermasalah yang mucul dalam kegiatan perbankan.(Putra, 2015)

perkembangan jumlah NPL (non performing loans) atau rasio kredit bermasalah. Berdasarkan ketentuan bank Indonesia dalam surat edaran bank Indonesia No.12/11/DPNP Tahun 2010. Standar criteria yang ditetapkan bank Indonesia bahwa rasio kredit bermasalah tidak boleh melebihi 5\% konidisi NPL.

Oleh sebab itu Bank Nagari Cabang Pembantu Simpang Haru harus menerapkan Majamenen Resiko Kredit terutama pada bagian kredit, untuk meminimalisir terjadinya kredit bermasalah dalam pengembalian kredit dari debitur.

Berdasarkan latar belakang permasalahan diatas, maka penulis tertarikmelakukanpenelitiandalambentuktugasakhirdengan judul "Analisis Manajemen Resiko Kredit Sebagai Alat Untuk Meminimalisir Risiko Kredit”

\section{Metode Penelitian}

\section{Metode Pengumulan Data}

a. Studi Lapangan

Padapenelitianinidilakukandengancara meminta data kepada Bank Nagari Cabang Pembatu Simpang Haru, Mengenai Analisis Manajemen Resiko Kredit dan Meminialisir Resiko Kreditpada Bank Nagari Cabang Pembantu Simpang Haru.

b. Studi Kepustakaan

Penelitian ini dilakukan dengan mengumpulkan data dan menggunakan teori-teori yang berkaitan dengan masalah-masalah yang akan dibahas, berupa buku-buku yang berkaitan dengan masalah yang penulisangkat.(Firmansyah \& Fernos, 2015) 


\section{Metode Analisis Data}

Metode analisis data yang digunakan dalam penelitian ini adalah metode deskriptif dengan metode pendekatan kualitatif. Pada Bank Nagari Cabang Pembantu Simpang Haru.

\section{HASIL DAN PEMBAHASAN}

\section{Analisis Manajemen Kredit}

Penetapan manajemen kredit sangat penting bagi Bank, terutama pada Bank Nagari Cabang Pembantu Simpang Haru sudah baik, namun masih belum maksimal dalam perencanaan kredit serta proses pemberian kredit. Adapun manajemen kredit yang diterapkan pada Bank Nagari Cabang Pembantu Simpang Haru yaitu:

\section{a. Perencanaan Kredit}

Penetapan perencanaan kredit sangat penting bagi dunia Bank, khusunya pada Bank Nagari Cabang Pembantu Simpang Haru, penetapan perencanaan kredit pada Bank Nagari Cabang Pembantu Simpang Haru sudah cukup baik, tetapi belum dapat diartikan maksimal, penerapan bertujuan untuk meningkatkan kualitas kredit yang baik serta menunjukan perumusan dan tujuan yang jelas, menyusun strategi, serta menetapkan sasaran yang dapat digunakan guna memprmudah Bank Nagari Cabang Pembantu Simpang Haru untuk mencapai tujuanya yang tidak lain agar dilunasinya pinjaman debitur serta dapat meminimalisir risiko kredit atau kredit bermasalah.(Lihani, 2013)

\section{b. Organisasi Kredit}

Pengorganisasi yang diterapkan oleh Bank Nagari Cabang Pembantu Simpang Haru sudah bagus, sesuai dengan yang diterapkan seperti Komite Kredit, Komite Kredit terdiri dari Analisis Kredit dan Aparat Pimpinan dalam pengorganisasi kredit pada Bank Nagari Cabang Pembantu Simpang Haru.

\section{c. Proses Pemberian Kredit}

Proses pemberian kredit yang diterapkan oleh Bank Nagari Cabang Pembantu Simpang Haru sudah cukup baik yaitu pengawasan kredit, jaminan kredit, serta syarat-syarat yang harus dipenuhi. (Lihani, 2013).(Lihani, 2013)

\section{Analisis Manajemen Risiko Kredit}

\section{a. Identifikasi Risiko Kredit}

Permasalahaan Risiko Kredit yang mucul pada Bank Nagari Cabang Pembantu Simpang Haru yaitu Kredit Bermasalah. Dalam hal ini ada faktorfaktor risiko kredit diantaranya meliputi internal bank, debitur dan lainya. Dengan demikian pihak debitur menjadi sebuaf faktor yang sering muncul dan sangat diperhatikan dalam perhatian khusus. 


\section{b. Pengukuran Risiko Kredit}

Non perfoming loan (NPL) sangat penting untuk pengukuran risiko kredit pada Bank Nagari Cabang Pembantu Simpang Haru, karena harus sesuai dengan ketentuan yang berlaku oleh Bank Indonesia (BI), dengan menggunakan non perfoming loanmaka akan mudah bagi Bank untuk mengetahui kriteria dalam menganalisisr risiko kredit dimana bank indonesia menetapkan jumlah $\mathrm{Npl}$ maksimal sebesar 5\%. Kolekttabilitas kredit menjadi dasar dalam menghitung tingkat NPL.(Putra, 2015)

\section{c. Pemantauan Risiko Kredit}

Pemantauan risiko kredit yang dilakukan oleh Bank Nagari Cabang Pembantu Simpang Haru sudah cukup baik, dimana pemantau dilakukan oleh staf operasional kredit dan staf pemasaran yang bertugas menangani debitur. Pemantauan dilakukan terhadap usaha debitur apakah sesuai dengan ketentuan dan tujuan diberikanya kredit. Kegiatan penyaluran kredit pada Bank Nagari Cabang Pembantu Simpang Haru juga dimonitor oleh otoritas jasa keuangan (OJK) dengan tujuan untuk mengetahui kelancaran kredit pada Bank Nagari Cabang Pembantu Simpang Haru.

\section{d. Pengendalian Risiko Kredit}

Bank Nagari Cabang Pembantu Simpang Haru sudah melakukan pengkajian ulang atau evaluasi terhadap pemberian kredit dan proses dalam administrasi kredit, dengan menggunakan standar kualitas dan pedoman yang sudah diterapkan. Dengan proses yang diterapkan ada dua jenis anggunan, kredit jenis umum dan asuransi jiwa untuk kredit kepegawaian. Pengendalian risiko kredit dari segi prosesnya sudah dilakukan dengan baik yaitu intern.(Tengor et al., 2015)

3. Analisis Data Kolektabilitas Kredit Dan Presentase Non Performing Loan (NPL)

\section{a. Tingkat Kolektabilitas Kredit}

Tingkat kolekbilitas kredit bermasalah pada Bank Nagari Cabang Pembantu Simpang Haru meliputi kolektabilitas antara lain Kurang Lancar, Diragukan dan Macet. Berdasarkan kolektabilitas keterlembatan pembayaran angsuran seperti Kurang Lancar dengan kategori terlambat dimulai dari 3 bulan sampai dengan 6 bulan, Diragukan apabila keterlambatan dari 6 bulan sampai 12 bulan, dan Macet dengan Keterlambatan lebih dari 12 bulan.(Lihani, 2013)

\section{b. Non Performing Loan ( NPL)}

Menurut Ismail (2009:224), kredit bermasalah yaitu suatu keadaan dimana nasabah sudah tidak sanggup membayar sebagian atau seluruh kewajibannya kepada bank seperti yang telah diperjanjikan.

Non Perfoming Loan (NPL)

NPL = Jumlah Kredit Bermasalah X 100\%

Jumlah Kredit 
Tabel 3.1

Data Persentase Non Performing Loan (NPL) pada Bank Nagari Cabang Pembantu Simpang Haru periode 2016-2018

(Dalam Rp. 000)

\begin{tabular}{|c|r|r|r|r|r|r|}
\hline \multirow{2}{*}{ Tahun } & \multicolumn{3}{|c|}{ Kredit Bermasalah } & \multicolumn{1}{c|}{$\begin{array}{c}\text { Jumlah } \\
\text { Kredit } \\
\text { Bermasalah }\end{array}$} & $\begin{array}{l}\text { Jumlah } \\
\text { Kredit }\end{array}$ & NPL \\
\cline { 2 - 7 } & $\begin{array}{c}\text { Kurang } \\
\text { Lancar }\end{array}$ & Diragukan & Macet & Bermany & \\
\hline 2016 & 5.477 & 14.624 & 1.513 & 21.614 & 127.135 & $0.17 \%$ \\
\hline 2017 & - & 14.437 & 1.437 & 15.874 & 107.548 & $0.14 \%$ \\
\hline 2018 & 679.719 & 1.280 & 94.739 & 775.198 & 4.690 & $1.65 \%$ \\
\hline
\end{tabular}

Sumber: Bank Nagari Cabang Pembantu Simpang Haru, Data diolah

Dari tabel 3.1 diatas terlihat jumlah kolektabilitas kredit bermasalah pada tahun 2016-2018 mengalami fluktuasi yang artinya naik turun nya jumlah NPL, sedangkan jumlah kredit tertinggi terjadi pada tahun 2016 sebesar Rp. 127.135, tetapi tingginya kredit juga di ikuti oleh kredit bermasalah juga ikut naik pada tahun 2016 .

Jumlah NPL pada tahun 2017 mengalami penurunan dan mengalami peningkatan pada tahun 2018 dimana pada tahun 2017 NPL berjumlah $0.14 \%$ dan pada tahun 2018 sebesar 1.65\%. dari tabel 3.1 dapat kita ambil persentase NPL seperti : $0.17 \%, 0.14 \%$ dan $1.65 \%$.

Dengan adanya data diatas dapat kita ketahui NPL mengalami peningkatan, tetapi masih aman karena tidak melampaui batas 5\% yang telah ditetapkan oleh Bank Indonesia (BI). Dari peningkatan diatas dapat kita lihat peningkatan NPL tertinggi terjadi pada tahun 2018 dimana jumlah NPL sebesar $1.65 \%$ dan jumlah NPL terendah terjadi pada tahun 2017 sebesar $0.14 \%$ sedangkah pada tahun 2016 jumlah NPL sebesar $0.17 \%$, dari tahun diatas dapat kita bandingkan bahwa NPL dari tahun 2016-2017 masih baik, karena kecil dari $5 \%$ jumlah NPL yang sudah ditetapka Bank Indonesia (BI). Namun akan lebih baik hal ini harus tetap diwaspadai agar tidak terjadinya peningkatan NPL agar jumlah kredit bermasalah tidak mengalami peningkatan kembali atau mengalami fluktuasi.

\section{SIMPULAN}

Dalam menerapkan manajemen risiko kredit Bank Nagari Cabang Pembantu Simpang Haru meliputi Identifikasi, pengukuran, pemantauan, serta pengendakian risiko Kredit. Ada faktor yang muncul dari risiko kredit adalah risiko Kredit bermasalah dimana pihak debitur harus dalam pengawalan khusus sedangkan pengukuran kredit harus sesuai dengan NPL, Non perfoming loan 
(NPL) sangat penting untuk pengukuran risiko kredit pada Bank Nagari Cabang Pembantu Simpang Haru, karena harus sesuai dengan ketentuan yang berlaku oleh Bank Indonesia (BI), dengan menggunakan non perfoming loan maka akan mudah bagi Bank untuk mengetahui kriteria dalam menganalisisr risiko kredit dimana bank indonesia menetapkan jumlah $\mathrm{Npl}$ maksimal sebesar $5 \%$. Kolekttabilitas kredit menjadi dasar dalam menghitung tingkat NPL.

Permasalahaan Risiko Kredit yang mucul pada Bank Nagari Cabang Pembantu Simpang Haru yaitu Kredit Bermasalah. Dalam hal ini ada faktorfaktor risiko kredit diantaranya meliputi internal bank, debitur dan lainya. Dengan demikian pihak debitur menjadi sebuah faktor yang sering muncul dan sangat diperhatikan dalam perhatian khusus.

\section{DAFTAR PUSTAKA}

Alanshari, F., \& Marlius, D. (2018). Prosedur Pemberian Kredit KPR Pada PT. Bank Tabungan Negara (Persero) TBK Cabang Pembantu Bukittinggi. https://doi.org/10.31227/osf.io/rsfhc

Afriyeni, A., \& Marlius, D. (2019). Analisis Tingkat Pengembalian Dan Risiko Investasi (Studi Pada Industri Manufaktur Yang Terdaftar Di Bursa Efek Indonesia). https://doi.org/10.31219/osf.io/cfb92

Amelia, L., \& Marlius, D. (2018). Pengendalian Kredit Dalam Upaya Menciptakan Bank Yang Sehat Pada PT. Bank Pembangunan Daerah Sumatera Barat Cabang Utama Padang. https://doi.org/10.31227/osf.io/kpc64

Fathoni, N. (2014). Manajemen Risiko Pembiayan Murabahah Di Pt Bprs Sukowati Kantor Cabang Boyolali. Peraturan Menteri Kesehatan Republik Indonesia Nomor 75 Tahun 2014 tentang Pusat Kesehatan Masyarakat. https://doi.org/10.1038/132817a0

Firmansyah, A., \& Fernos, J. (2015). Analisis Kredit Bermasalah Dilihat Dari Standar Non Performing Loan ( Npl ) Pada Pt . Bank Perkreditan Rakyat ( Bpr ) Prima Mulia. 1 of 13.

Ikbal, M., \& Marlius, D. (2017). Pengaruh Jumlah Taksiran Dan Uang Pinjaman Terhadap Laba Bersih Pada PT. Pegadaian (UPC) Gurun Laweh. https://doi.org/10.31227/osf.io/uch4a

Kasmir, D. (2014). Bank Dan Lembaga Keuangan Lainya.

Lihani, R. (2013). Analisis Manajemen Kredit Guna Meminimalisir Risiko Kredit. 26(4), 1-37.

Muharam, H. (n.d.). Model Risiko Kredit: Pendekatan Dan Faktor-faktor Yang Mempengaruhinya.

Putra, S. P. (2015). Analisis Manajemen Risiko Kredit Sebagai Alat Untuk Meminimalisir Risiko Kredit (Studi Kasus Pada PT. Bank Perkreditan Rakyat Dau Kusumadjaja Malang).Jurnal Administrasi Bisnis S1 Universitas Brawijaya, 26(2), 86299.

Putri, F. S. (2013). Pengaruh Risiko Kredit Dan Tingkat Kecukupan Modal Terhadap Tingkat Profitabilitas Pada Perusahaan Perbankan Yang Terdaftar Di Bursa 
Efek Indonesia.

Savitri, O. A. (2014). Analisis Manajemen Risiko Kredit Dalam Meminimalisir Kredit Bermasalah Pada Kredit Usaha Rakyat (Studi pada Bank Jatim Cabang Mojokerto).Jurnal Administrasi Bisnis S1 Universitas Brawijaya, 12(1), 83247.

Shanjaya, A. R., \& Marlius, D. (2017). Peranan Laporan Keuangan Dalam Kebijaksanaan Pemberian Kredit Kepada Calon Nasabah Pada PT. BPR Batang Kapas. https://doi.org/10.31227/osf.io/uxmg6

Tengor, R., Murni, S., \& Moniharapon, S. (2015). Penerapan Manajemen Risiko Untuk Meminimalisir Risiko Kredit Macet Pada PT. Bank Sulutgo.Jurnal Riset Ekonomi, Manajemen, Bisnis Dan Akuntansi, 3(4), 345-356. 